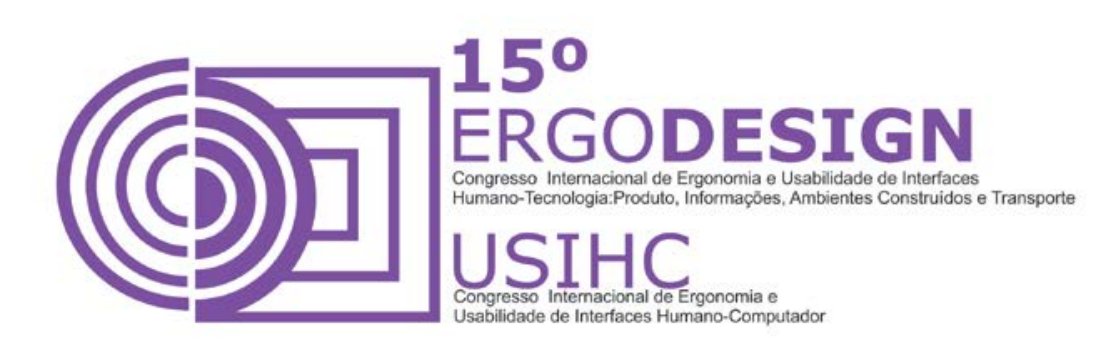

\title{
DESIGN CONTEXTUAL: UM ESTUDO DE UM SISTEMA DE TRANSPORTE URBANO SOB A ÓTICA DO DESIGN CENTRADO NO USUÁRIO
}

\section{CONTEXTUAL DESIGN: A STUDY OF AN URBAN TRANSPORT SYSTEM FROM THE PERSPECTIVE OF USER-CENTERED DESIGN}

\author{
PASSOS, Marcel de Oliveira (1); \\ SANTA ROSA, José Guilherme (2) \\ (1) Universidade Federal do Rio Grande do Norte, Bacharel em Design \\ e-mail: marcelspassos@gmail.com
(2) Universidade Federal do Rio Grande do Norte, Doutor em Ensino de Ciências e Mestre em Design. \\ e-mail: jguilhermesantarosa@gmail.com
}

\begin{abstract}
RESUMO
Este artigo visa demonstrar o processo de pesquisa e análise do comportamento de usuários do transporte público da cidade de Natal-RN a fim de elucidar problemáticas e modelar a interação entre os usuários e o sistema em si. A pesquisa foi fundamentada nos conceitos de Design Centrado no Usuário e contou com a participação dos usuários estudantes universitários por meio de Grupos de Foco e Observação participante. Destacase que todo o processo foi sintetizado por meio da elaboração de modelos baseados no Design Contextual.
\end{abstract}

Palavras-Chave: design centrado no usuário, design contextual, grupo focal, observações participantes, mobilidade urbana.

\section{ABSTRACT}

This paper aims to demonstrate the process of research and analysis of public transport users behavior of Natal-RN in order to elucidate problems and model the interaction between users and the system itself. The research was based on the concepts of User-Centered 


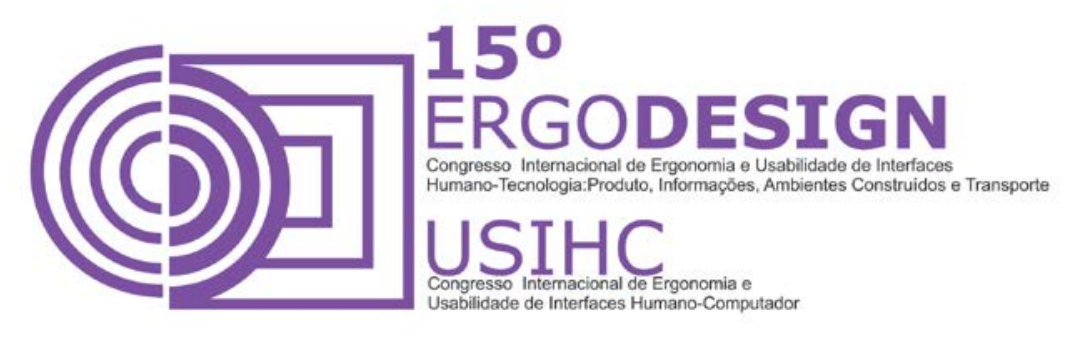

Design and with the participation of university students users through focus groups and participant observation. It is noteworthy that the whole process was synthesized through the development of models based on Contextual Design.

Keywords: user-centered design, contextual design, focus group, participatory observations, urban mobility.

\section{INTRODUÇÃO}

Natal é considerada uma metrópole cuja população ultrapassa 800 mil pessoas (IBGE, 2014). Sua economia é proveniente principalmente dos setores: turismo, têxtil, construção civil e comércio.

Além dos interesses econômicos em comum com sete municípios do seu entorno, Natal possui uma movimentação intensa de pessoas que fazem o percurso diário para trabalhar, usufruir de infraestruturas básicas como escolas e hospitais, bem como ter acesso a bens materiais. Resultando, portanto, num movimento pendular onde as pessoas se movimentam entre as cidades, mas não chegam a mudar suas residências. Fica evidente a necessidade de um sistema de transporte público eficiente para oferecer autonomia para esta população, autonomia esta respaldada pela lei 15.587/12 do Senado Federal que prevê o planejamento de políticas públicas priorizando o uso de transporte coletivo e transporte não motorizado.

Sendo observada a dificuldade da população em utilizar o transporte público e, consequentemente, ter acesso a locais da cidade. Surgiu a oportunidade de se realizar uma pesquisa baseando-se nas premissas do Design Centrado no Usuário para que possam ser elencados motivações e constrangimentos dos usuários, pois “(...) suas metas são a força motriz por trás do desenvolvimento do produto" (PREECE, ROGERS E SHARPS, 2013).

\section{OBJETIVOS DA PESQUISA}

Tendo como premissa a falta de informação generalizada sobre as linhas e itinerários dos ônibus que circulam pela cidade, gerando, consequentemente, a impossibilidade de acesso a locais (conhecidos e desconhecidos) da cidade. Assim, o objetivo do trabalho é dialogar com os usuários para capturar suas expectativas, opiniões, motivações e constrangimentos relacionados ao uso do sistema de transporte público.

Devido à complexidade dos conceitos associadas à mobilidade e acessibilidade urbana, não é pretendido abordar o tema com profundidade neste trabalho. Apesar dos conceitos de mobilidade urbana estar, diretamente, atrelados ao comportamento do usuário. Além da visão da demanda por transporte público, a mobilidade urbana deve estar ligada "ás necessidades de deslocamento da população, principalmente daquela que depende do transporte público" (FORNECK E ZUCCOLOTTO apud RAIA, 2000). 


\section{(C))}

\section{MÉTODOS, TÉCNICAS E RESULTADOS}

O presente trabalho tem como objetivo principal realizar um estudo com cidadãos de NatalRN a fim de compreender o contexto de utilização do sistema de transporte urbano da cidade e, assim, entender seus constrangimentos e estratégias para lidar com as dificuldades relacionadas ao sistema. Para tanto, foram aplicadas as técnicas de 'grupo de foco' e 'observação participante' com um grupo de 20 estudantes universitários que residem em Natal/RN e que utilizam o ônibus para realizar deslocamentos à Universidade e a outros locais.

A partir das informações obtidas por meio das técnicas grupo focal e observação participante foi empregada a técnica Design Contextual com o intuito de identificar as relações estabelecidas pelos elementos que fazem parte dos contextos em que os usuários frequentam para atingir seus objetivos.

\subsection{Grupo de Foco}

A técnica de grupo de foco visa reunir possíveis futuros usuários do produto em desenvolvimento para captar suas opiniões, necessidades, constrangimentos, expectativas e suposições através de uma conversa informal, porém mediada por um responsável pelo projeto. Os grupos de foco podem elucidar tanto oportunidades quanto problemas sobre um produto ou sistema (CYBIS, BETIOL E FAUST, 2010). De acordo com SANTA ROSA e MORAES $\left(2010^{a}\right)$ consiste numa discussão estruturada em tópicos para que sejam dialogados entre todos os participantes e conduzidas por um moderador. É comum agruparem de dez a doze pessoas em um ambiente calmo e confortável, em sessões que duram aproximadamente duas horas.

Nesta pesquisa, foram realizadas três sessões com 15 estudantes universitários das áreas de Administração, Design, Letras e Ciências da Computação. Na faixa etária de 18 a 25 anos em locais propícios para este tipo de atividade: com mesas, cadeiras e poucos ruídos. Os tópicos utilizados para conduzir a discussão são:

a) Em sua opinião, qual a situação atual do sistema viário da cidade? (ônibus e alternativos); Podem nos contar pelo menos uma (1) experiência positiva e negativa com relação aos ônibus? Vocês já precisaram se dirigir a algum destino de ônibus, mas não sabiam qual linha pegar? Se sim, conte-nos essa experiência; O que vocês poderiam fazer caso estivessem nessa situação?

b) Vocês já tiveram dúvidas em encontrar paradas de ônibus ou, já estando dentro do veículo, tiveram dificuldade em saber onde descer? Se sim, como "sairam" dessa situação?

c) Como vocês costumam se orientar e se localizar dentro da cidade?

d) Vocês conhecem os itinerários dos ônibus que vocês costumam pegar no dia-a-dia? Como vocês se informam sobre os itinerários do ônibus?

e) Como vocês se informam sobre os horários dos ônibus? 


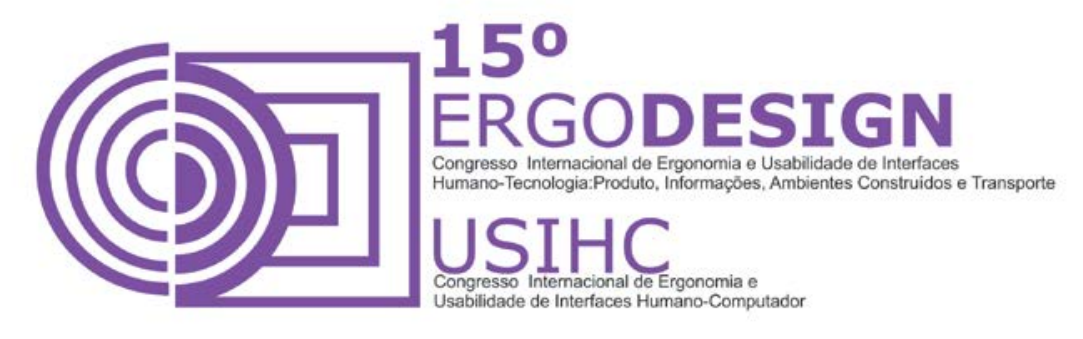

f) Que atividades vocês costumam usar smartphones como auxílio?

g) Como vocês utilizam seus telefones fora de lugares fechados (na rua)? Em quais situações e circunstâncias? Se não utilizam, por qual motivo?

h) Vocês costumam usar alguma ferramenta com GPS no smartphone? Como é a experiência?

i) O que vocês acham da possibilidade de usar o smartphone como ferramenta para se informar sobre linhas, itinerários e horários dos ônibus?

j) Selecionar pontos chaves da sessão para serem revisadas por todos

k) Agradecimentos

Uma vez registradas em áudio e vídeo, foram extraídas tendências dos assuntos mais abordados durantes as sessões. Estes assuntos foram agrupados em temas apresentados na tabela a seguir:

\begin{tabular}{|c|c|}
\hline $\begin{array}{l}\text { Questões } \\
\text { relacionadas às } \\
\text { empresas de } \\
\text { ônibus: }\end{array}$ & $\begin{array}{l}\text { Expressam insatisfação/desconforto em relação qualidade do serviço prestado pelas } \\
\text { empresas de ônibus } \\
\text { Mostra o mau atendimento/conduta dos motoristas em relação aos passageiros } \\
\text { Mostra o mau atendimento/conduta dos cobradores em relação aos passageiros } \\
\text { Expressam que administração das empresas não atendem as expectativas dos clientes } \\
\text { Sentem-se prejudicados/incomodados/confusos pelo planejamento dos horários dos ônibus } \\
\text { Sentem se prejudicados pelo excesso de pessoas nos ônibus } \\
\text { Sentem-se confusos/prejudicados pelas rotas que estabelecidas pelas empresas. } \\
\text { Sugerem soluções de melhorias em relação ao serviço das empresas } \\
\text { Questionam a qualidade física dos veículos das empresas } \\
\text { Consideram ineficientes/incompletas as informações disponibilizadas pelas empresas } \\
\text { Exprimem suas estratégias com relação aos horários dos ônibus }\end{array}$ \\
\hline $\begin{array}{l}\text { Questões } \\
\text { relacionadas ao } \\
\text { sistema de } \\
\text { mobilidade } \\
\text { urbana }\end{array}$ & $\begin{array}{l}\text { Expressa insatisfação/desconforto em relação à qualidade do sistema de mobilidade urbana } \\
\text { da cidade; } \\
\text { Questionam a eficiência de construções relacionadas à mobilidade urbana; } \\
\text { Criticam as estruturas das paradas; } \\
\text { Sugerem soluções para a mobilidade urbana; } \\
\text { Expressam desconforto/preocupação com relação à insegurança; } \\
\text { Criticam as ações administrativas do governo em relação à mobilidade urbana; } \\
\text { Sentem-se confusos em se localizar na cidade; } \\
\text { Exprimem opiniões favoráveis a ações do sistema de mobilidade urbana. }\end{array}$ \\
\hline
\end{tabular}




\section{(C)] ]

\begin{tabular}{|c|c|}
\hline $\begin{array}{l}\text { Questões } \\
\text { relacionadas à } \\
\text { interação com } \\
\text { aplicativos para } \\
\text { smartphone }\end{array}$ & $\begin{array}{l}\text { Sugerem funções ao aplicativo que está sendo projetado; } \\
\text { Discorrem sobre futuras situações em que aplicativo pode ser útil; }\end{array}$ \\
\hline $\begin{array}{l}\text { Comentam } \\
\text { sobre suas } \\
\text { estratégias para } \\
\text { buscar } \\
\text { informações } \\
\text { relacionadas ao } \\
\text { transporte } \\
\text { público e } \\
\text { localização } \\
\text { dentro da } \\
\text { cidade: }\end{array}$ & $\begin{array}{l}\text { Tentam obter informações perguntando as pessoas nas ruas/paradas/dentro do ônibus; } \\
\text { Tentam obter informações perguntando para cobradores/motoristas no ônibus; } \\
\text { Pesquisam na internet; } \\
\text { Utilizam aplicativos mobile. }\end{array}$ \\
\hline $\begin{array}{l}\text { Questões } \\
\text { relacionadas à } \\
\text { população em } \\
\text { geral }\end{array}$ & $\begin{array}{l}\text { Exprimem opiniões a cerca do nível de informação da população relacionada ao transporte } \\
\text { público da cidade. }\end{array}$ \\
\hline
\end{tabular}

\subsection{Observação Participante}

A observação participante é uma técnica derivada da etnografia efetuada nos estágios iniciais do projeto, na qual são realizadas observações qualitativas sobre as ações dos pretensos usuários em cenários reais de uso. Permitindo que o pesquisador vivencie e intervenha em situações específicas questionando suas motivações e implicações. A observação participante propicia uma noção a respeito do ambiente físico, organizacional, sócio cultural e econômico em que o usuário está inserido (SANTA ROSA e MORAES, 2012b).

A observação participante é realizada, basicamente, em duas etapas: observação e entrevistas. O pesquisador adotar níveis diferentes de participação, sendo apenas observador até total participante. Recomenda-se adotar uma posição de aprendiz-mestre a fim de captar com precisão as atividades observadas, sem incluir pensamentos e opiniões 


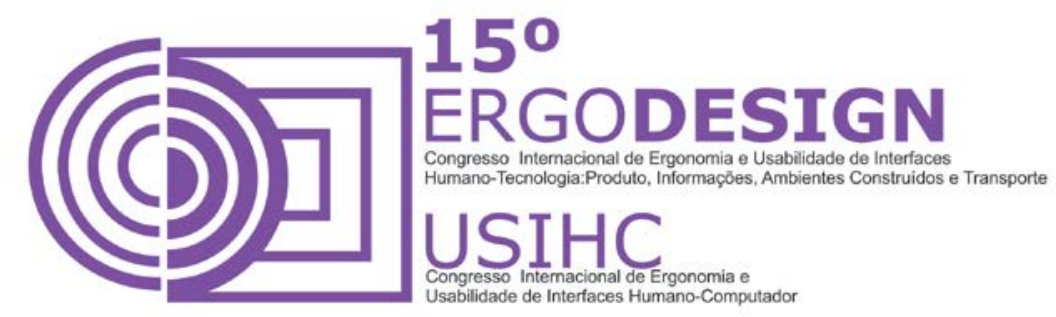

por parte dos pesquisadores. Já as entrevistas podem assumir caráter aberto para inferir nas situações observadas (ANGROSINO, 2009).

Os dados foram captados em dois dias diferentes de pesquisa em campo, ao total de oito horas de atividade de observação e 20 entrevistas. As observações foram conduzidas em dois locais diferentes na cidade de Natal - RN. Dois pontos de ônibus que se destacam pela grande quantidade de pessoas que circulam no local durante o dia:

- Local 1: Central de Transferência, localizada na avenida Salgado Filho. Próximo aos shoppings Via Direta e Natal Shopping. Zona Sul da Cidade.

- Local 2: Ponto de ônibus localizado em frente ao Midway Mall. Também na Avenida Salgado Filho, zona leste da cidade. Em frente ao Instituto Federal do Rio Grande do Norte.

A seguir são apresentados os tópicos abordados na etapa de entrevistas:

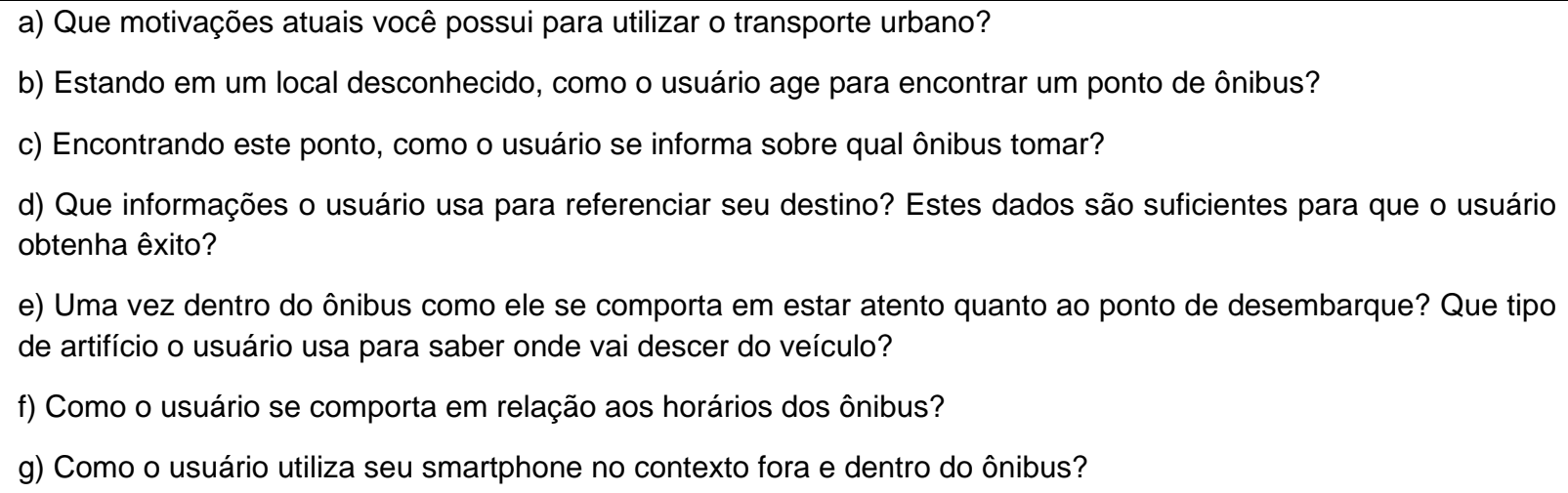

Por meio técnica 'observação participante' foi possível perceber alguns padrões de comportamento relativamente comuns exercidos pelos usuários entrevistados:

- Utilizam o transporte público por "não ter outra opção". Costumam ir à universidade, shopping e praia;

- Costumam sair com bastante antecedência para pegar o ônibus;

- Normalmente perguntam as pessoas sobre linhas, locais e paradas. Geralmente não conseguem ver placas, então recorrem às pessoas na rua;

- Perguntam ao cobrador ou a pessoas ao redor para saber onde descer do ônibus;

- Consideram importante saber sobre os horários para não perder compromissos, contudo não encontram as informações em um local de fácil acesso e confiável. Geralmente não possuem conhecimento sobre os horários; 


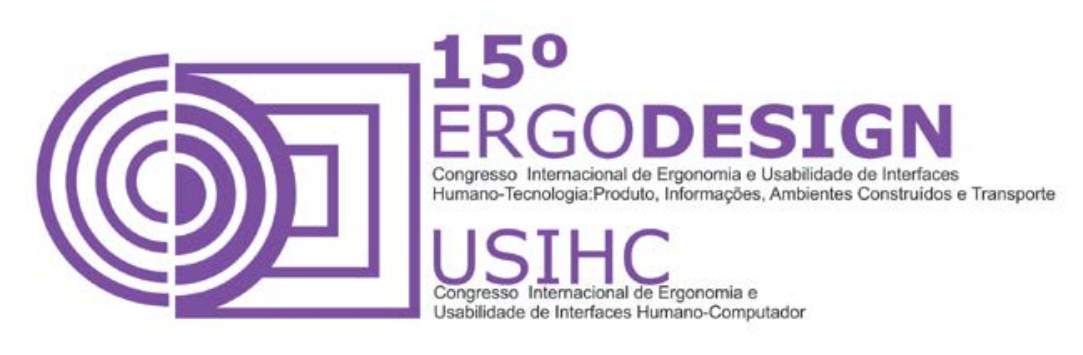

- Alguns não costumam utilizar o smartphone em ambientes muito movimentados;

- Normalmente prestam atenção aos pontos de referências para saber onde ficam as paradas. Alguns, quando não conhecem o local, costuma utilizar o o GPS do celular.

\subsection{Design Contextual}

Design Contextual é uma abordagem para coleta de dados no contexto dos usuários, interpretação e consolidação de forma estruturada. O principal objetivo do design contextual é entender os objetivos fundamentais, desejos e motivações. Porém isto não é facilmente visível, só podendo, portanto, ser verificando em campo, perguntando aos usuários (HOLTZBLATT E BEYER, 2013). Portanto, os resultados obtidos por meio do grupo de foco e da observação participante foram organizados em 4 modelos, dos 5 propostos por (HOLTZBLATT e BEYER, 2013):

- Modelo de Fluxo: captura a comunicação e coordenação para completar um trabalho. Revelam os grupos de trabalhos (formais e informais), pontos críticos da comunicação e divisões de responsabilidades (formais e informais) para completar tarefas;

- Modelo Cultural: mostra as políticas culturais que constrangem execução do trabalho. Como estes constrangimentos afetam os usuários e quais suas estratégias para contornar estas situações;

- Modelo sequencial: exibe detalhadamente a sequência de passos, suas estratégias e dificuldades para completar cada etapa de um trabalho.

- Modelo físico: apresenta os ambientes físicos utilizados para impedir ou completar a um trabalho.

- Modelo de artefatos: apresenta os artefatos que são criados e utilizados para efetivar um trabalho.

A seguir são apresentados os modelos elaborados a partir dos resultados obtidos na pesquisa, organizados sob a ótica da abordagem do Design Contextual:

\subsubsection{MODELO FÍSICO}

A partir dos dados levantados, existe quatro locais gerais que servem como etapas para o usuário cumprir seus objetivos. O primeiro é o local de origem, ou local de partida, que seria 


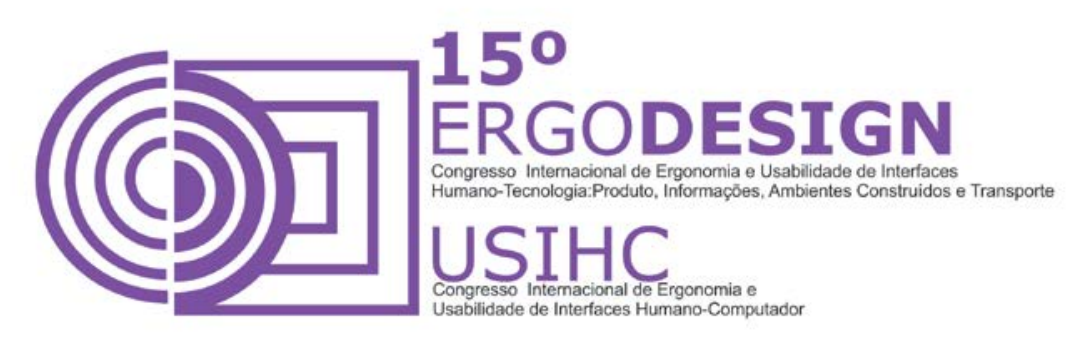

o lugar onde o usuário procura as primeiras informações sobre o seu destino: seja perguntando a amigos e familiares, seja procurando referências do local no Google Maps. Logo após, o usuário precisa se dirigir ao ponto de ônibus, onde é possível se informar com outras pessoas que lá se encontram, inclusive vendedores (figura 1). Após esta etapa, o usuário embarca no ônibus que ele acredita que vá chegar ao seu destino, dentro do veiculo ele pode obter orientações com o motorista e o cobrador. Depois de descer, ele provavelmente precisará percorrer algum trecho a pé, existe, portanto, mais uma oportunidade de obter orientações para chegar ao destino.
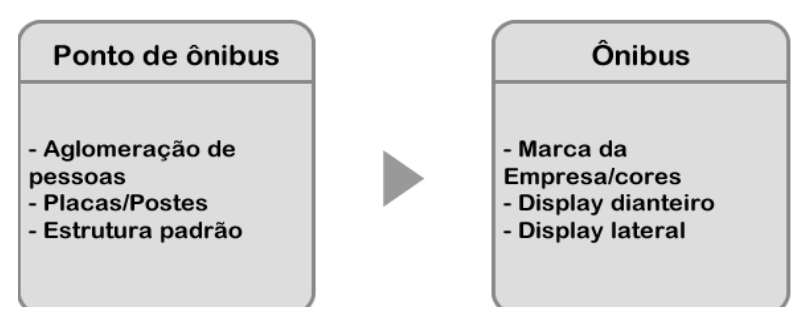

Figura 1. Modelo Físico

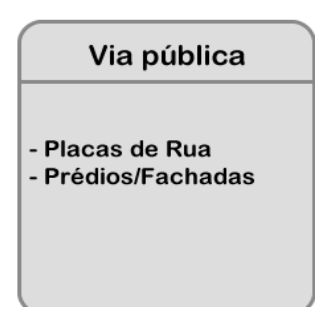

\subsubsection{MODELO FLUXO}

É possível identificar os diferentes atores envolvidos na atividade de usar o transporte público (figura 2): a) os motoristas de ônibus, b) o Cobrador, c) o Transeunte; d) o Vendedor e e) o usuário em si. As inter-relações e interações entre os atores podem ser visualizadas no modelo a seguir: 

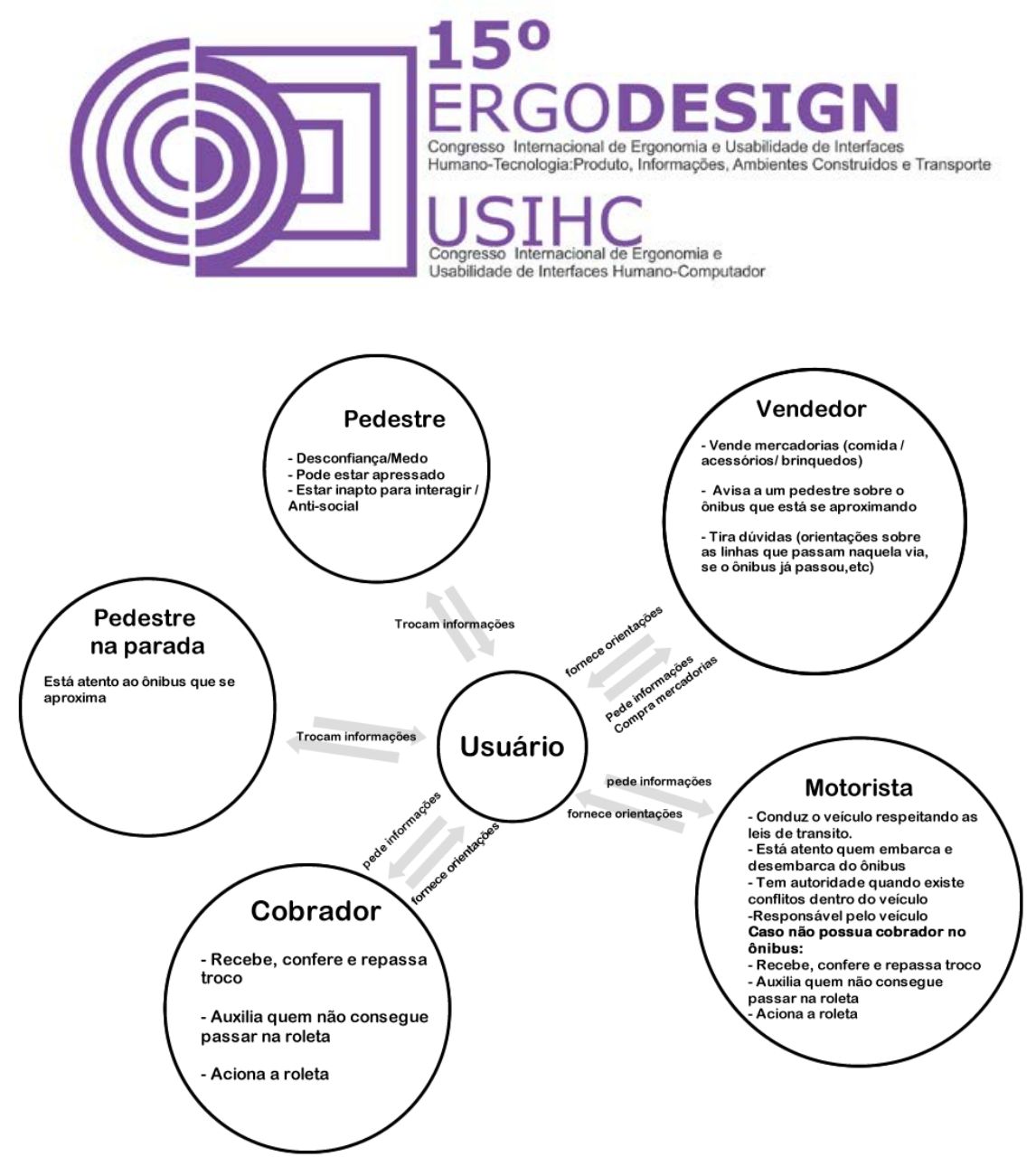

Figura 2. Modelo Fluxo

\subsubsection{MODELO SEQUENCIAL}

De acordo com a sequencia de ações, pode-se perceber que existe diferentes contextos físicos que o usuário precisa estar para completar seu objetivo. A criação desse fluxograma, portanto, visa mostrar detalhadamente suas ações nestes cenários (figura 3).

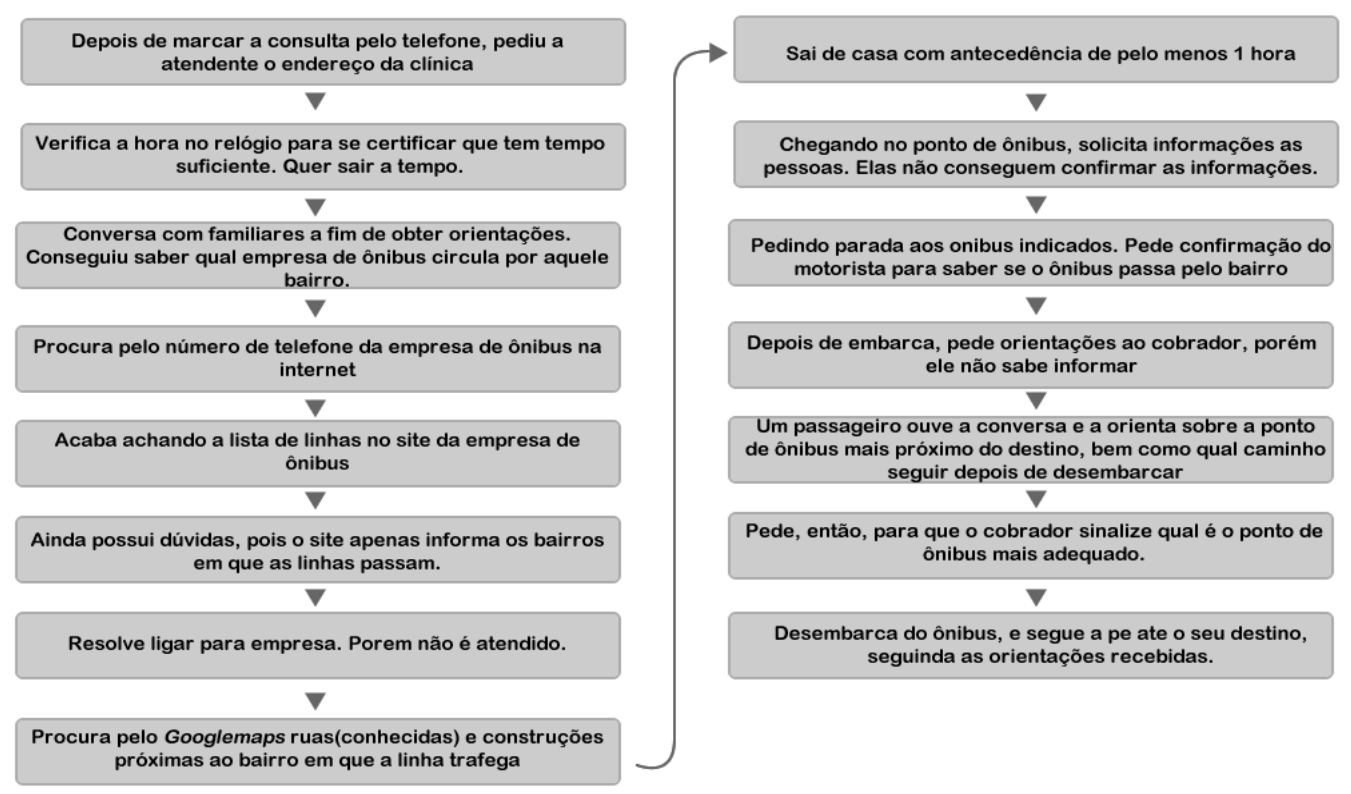




\section{((D) 1 (C) $^{150}$ ERGDESIGN}

Figura 3. Modelo Sequencial

\subsubsection{MODELO CULTURAL}

Com o modelo cultural (figura 4), podemos elucidar restrições (Culturais, éticas) que podem atrapalhar as possíveis interações entre os atores que fazem parte deste cenário específico. O usuário e o transeunte possuem, basicamente, as mesmas restrições: Não saber dar a informação que está sendo requisitado, ter desconfiança/medo da pessoa que está abordando, estar inapto para relações sociais no dia, pode não falar o idioma de quem está perguntando, assim em diante. O cobrador recebe, verifica e devolve troco dos passageiros, orienta os passageiros que não conseguem usar a máquina leitora de cartão e aciona a roleta. O motorista precisa conduzir o veículo, respeitar as leis de trânsito, controlar as portas para embarque e desembarque dos passageiros. Quando não é auxiliado por um cobrador, precisa executar a atividade de contar o dinheiro e devolver o troco, além de auxiliar os passageiros que não conseguem utilizar a máquina e acionar a roleta. E, por último, o vendedor preocupa-se em atender a clientela que procura seu produto.

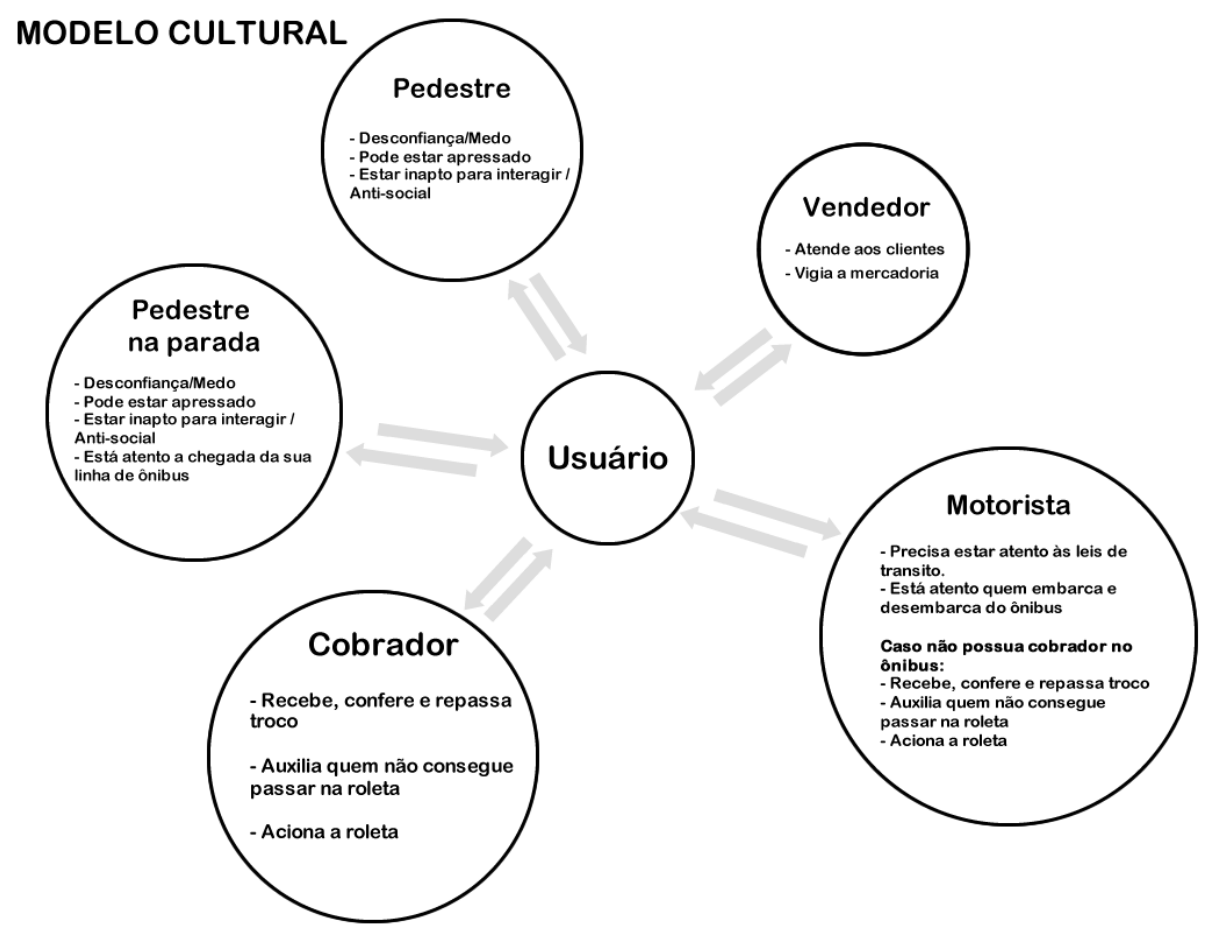

Figura 4. Modelo Cultural 


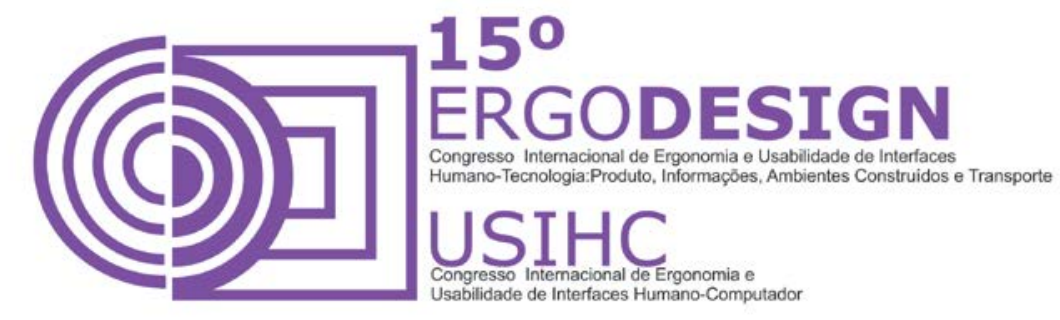

Cabe ressaltar que o modelo de artefatos não foi considerado pois foi estabelecido como recorte do presente trabalho a identificação de requisitos, necessidades e percepções dos usuários a respeito do sistema de transporte público da cidade de Natal, RN.

\section{CONCLUSÃO}

A técnica de grupo de foco, aplicada na presente pesquisa, contribuiu para que pudéssemos elencar necessidades, problemáticas gerais, bem como obter informações a respeito dos constrangimentos vivenciados por usuários no uso de dispositivos móveis em lugares abertos. Os resultados do grupo de foco, ulteriormente, foram utilizados para a elaboração do roteiro para aplicação da técnica 'observação participante'.

Com a análise das sessões de grupo de foco, além de elencarmos alguns padrões de comportamento e situações de constrangimentos que serviram para o roteiro de observação participante. Esta técnica, derivada dos estudos antropológicos e visa compreender as ações da população no contexto real, como atividade complementar temos as entrevistas que propicia a interferência do pesquisador em questionar o que os indivíduos pesquisados estão fazendo e o que eles querem alcançar com tal atitude. Assim, os padrões captados nas sessões de grupo de foco serviram como premissas de investigação na parte das observações participantes para serem confirmadas ou refutadas. Haja vista que, apesar de nos limitarmos à amostra de 20 entrevistas, as informações colhidas nas sessões de grupo de foco foram confirmadas pela observação no contexto dos usuários e pelas entrevistas, ao ponto das informações tornarem-se captadas estarem se repetindo.

Dentro do processo, com o uso do design contextual foi possível elencar os elementos e participantes do cenário, bem como elucidar seus relacionamentos em diversos aspectos como, por exemplo, culturais. Vale salientar que informações como estas não são levadas em consideração na maioria dos projetos, e a observância destes critérios podem nos mostrar que esses "detalhes" (considerados irrelevantes) podem representar o fracasso de um design. Ressalta-se que, devido à complexidade dos conceitos associadas à mobilidade e acessibilidade urbana e da quantidade de entidades envolvidas no processo, o estudo visou captar somente informações sob o ponto de vista do usuário do sistema de transporte público - sem incluir a visão dos gestores de políticas públicas responsáveis pelo planejamento e implantação dos projetos de mobilidade urbana nem dos empresários responsáveis pelos ônibus que circulam na cidade.

\section{REFERÊNCIAS}




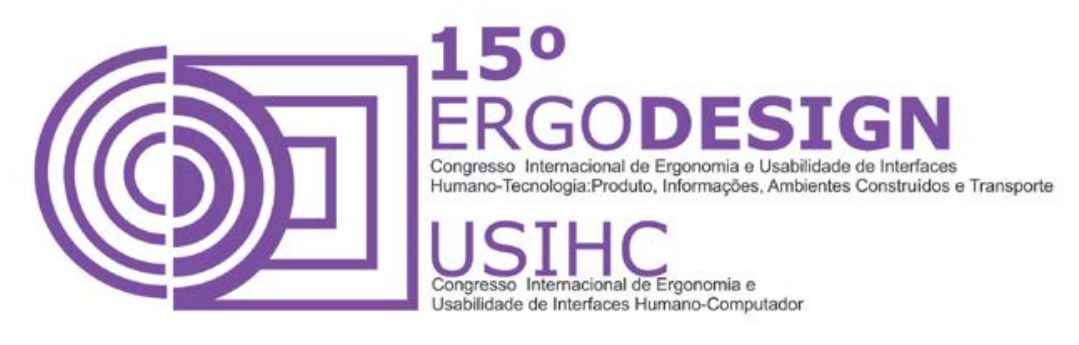

CYBIS, W., BETIOL, A., FAUST, F. ERGONOMIA E USABILIDADE: CONHECIMENTOS, METODOS E APLICAÇOES. $2^{\mathrm{a}}$ Ed. Florianópolis: Novatec, 2010.

HOLTZBLATT, Karen. e BEYER, Hugh. Contextual Design. Disponível em:

$<$ https://www.interaction-design.org/encyclopedia/contextual design.html> Acesso em: 25 out 2014.

IBGE. Cidades: Informações completas. Disponível em: <

http://cidades.ibge.gov.br/xtras/perfil.php?codmun=240810> Acesso em: 16 dez 2014.

PREECE, Jenifer, ROGERS, Yvonne e SHARP, Helen. Design de Interação - além da interação humano computador. New York: John Wiley \& Sons, Inc. 3ª Ed, 2013.

RAIA, Arquimedes. Acessibilidade e Mobilidade na estimativa de um índice de potencial de viagens utilizando Redes Neurais Artificiais e Sistemas de Informações Geográficas. São Carlos, 2000. Disponível em:

<www.teses.usp.br/teses/disponiveis/18/18137/tde.../RaiaJrT.PDF> Acesso em 15 dez. 2014.

SANTA-ROSA, José Guilherme e MORAES, Ana Maria. Avaliação e Projeto no Design de Interfaces. Rio de Janeiro: 2ab, 2012a.

SANTA-ROSA, José Guilherme e MORAES, Ana Maria. Design Participativo. Rio de Janeiro: Rio Books, 2012b. 